based on a proportionate change in total calcium with protein rather than an absolute change. A slightly improved nomogram would be based on the plasma albumin rather than the total protein and would be derived from the known calcium-albumin association constant. Such a nomogram can be prepared by any physical chemist and will be included by us in a forthcoming publication.-We are, etc.,

R. W. MARSHALL
B. E. C. NORDIN

M.R.C. Mineral Metabolism Unit, General Infirmary,

Leeds

\section{Ketotic Hypoglycaemia}

SIR,-Ketotic hypoglycaemia occurs in undergrown infants and children, many of whom were small at birth. The hypoglycaemia is intermittent, occurring after a short period of calorie deprivation. It is sometimes associated with periods of increased calorie requirements such as anorexia associated with a minor infection. The biochemical hallmarks are found only during the hypoglycaemia; they include ketonuria and the failure of intramuscular glucagon to increase the blood gluoose, while hypoalaninaemia may also occur. The basic defect is not known, though an error of metabolism has been extensively sought. Hepatic gluooneogenesis from glycerol, fructose, and alanine is intact, ketone metabolism is normal, and hormone responses appear to be appropriate with the possible exception of reduced catecholamine excretion in some children. The hypoglycaemia gradually disappears during childhood and is suocessfully treated with corticosteroids. The unique identity of this disorder is questioned by some authors ${ }^{1}$ since similar ketonuria and lowering of blood glucose are seen in normal children during a prolonged ketogenic diet or starvation.

Most of these children have a normal fonehead size. Glucose nequinements cenebral metabolism are therefore high relative to the small body size, either during normal feeding or during starvation. I have never seen this condition in a robust and well-nourished child and I am led to oonsider whether the problem is not purely one of nutrition rather than an inborn error of metabolism.

In a 2-year-old child weighing $12 \mathrm{~kg}$ the normal energy requirement would be around $50 \mathrm{kcal} / \mathrm{hr}$. In the face of total glycogen depletion about $50 \%$ of this would come from alanine $(5-7 \mathrm{~g} / \mathrm{hr})$ derived from pyruvate and amino-acids in the muscle These patients are carbohydrate-depleted, as shown by the exhaustion of the hepatic glycogen reserves. In view of their smal size and muscle mass it seems reasonable to postulate a deficiency in total available muscle amino-acids which could result in the hypoalaninaemia and consequently in hypoglycaemia.

Hypoglycaemia may occur in overt malnutrition and Schutt-Aine has reported it in maternally deprived children. ${ }^{2}$ We have occasionally observed ketotic hypoglycaemia in neglected children. Sizonenko et al..$^{3}$ have also shown that after a period of unrestricted feeding children with previous ketotic hypoglycaemia respond to fasting and glucagon administration in a normal fashion. These findings seem to indicate that ketotic hypoglycaemia is yet another facet of nutritional deprivation rather than an inherent defect in glucose homoeostasis.-I am, etc.

NEIL R. M. BUIST

Department of Pediatrics

University of Oiegon Medical School, ortland, Oregon Schutt-Aine, J. C., Drash, L., and K
fournal of Pediatrics, $1973,82,809$.

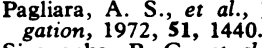

(1440. $7,983$.

\section{Deep Venous Thrombosis: a Hypothesis}

SIR,-I wonder whether a case which happened some years ago in my own experience fits the hypothesis put forward by Mr. J. Charnley (1 June, p. 499).

A woman aged 58 had an emergency operation for a ruptured cystic ovarian granulosa cell tumour on 2 July 1963 . She had a mild degree of rheumatoid arthritis and was taking phenylbutazone at the time of admission to hospital. Her recovery following the operation was quite uneventful and she was discharged from hospital on 16 July. On 17 August she was readmitted with severe pain in her chest, worse on deep breathing. We did not tumble to the diagnosis until five days later, when we discovered in the morning that she had a very
swollen, painful, blue leg, undoubtedly due to a swollen, painful, blue leg, undoubtedly due to a left iliac vein thrombosis. We immediately concluded that the preceding chest pain must have been due to an embolism. Treatment with antithe leg and the chest to disappear within four weeks.

The interesting point is the chronological sequence-the obvious embolism preceding the obvious thrombosis. What I thought was that she must have had a symptomless thrombosis in the deep veins of either the pelvis or the lower limb. I imagined a long, snake-like clot floating in the blood, part of it becoming detached or else growing long enough to reach the point where the vein joined one of the major veins of the lower limb. There perhaps it coiled up or flapped over the point of confluenoe with the larger vein suddenly blocking it.-I am, etc.,

BRUCE ETON

Buchanan Hospital,

St. Leonards-on-Sea,

Sussex

\section{Hypoglycaemia Action of Onion on Rabbits}

SIR,-We found ${ }^{1}$ that onion and garlic juice fed to rabbits resulted in a better utilization of glucose. We report here the results of a further investigation to see what effects various extracts of onion had on blood glucose levels in rabbits with alloxaninduced diabetes.

Fresh onions were cut into pieces, dried for 24 hours in a hot-air oven at a temperature of $60-80^{\circ} \mathrm{C}$, and then powdered. The powder was extracted in a Soxhlet apparatus successively with ethyl alcohol $95 \%$, petroleum ether $\left(B . P .40-60^{\circ} \mathrm{C}\right)$ chloroform, and acetone, each extraction lastin for a period of 18 hours. The powder was dried in a period oach extraction. The extracts were in between each extraction. The extracts were concentrated under vacuum and for hypoglycaemic effect.

\begin{tabular}{|c|c|c|c|c|c|c|}
\hline \multirow{2}{*}{ Test Substance } & \multicolumn{5}{|c|}{ Mean Blood Glucose Levels $(\mathrm{mg} / 100 \mathrm{ml})$ in 6 Rabbits } & \multirow{2}{*}{$\begin{array}{l}\text { Maximum \% Fall in } \\
\text { Fasting Blood Glucose } \\
( \pm \text { S.E.M. })\end{array}$} \\
\hline & Fasting & $1 \mathrm{hr}$ & $2 \mathrm{hr}$ & $3 \mathrm{hr}$ & $4 \mathrm{hr}$ & \\
\hline $\begin{array}{l}\text { Ethyl alcohol extract } \\
\text { Petroleum ether extract } \\
\text { Chloroform extract } \\
\text { Acetone extract } \\
\text { Distilled water (control) }\end{array}$ & $\begin{array}{l}210 \cdot 5 \\
218.4 \\
200 \cdot 0 \\
196.0 \\
205 \cdot 0\end{array}$ & $\begin{array}{l}204 \cdot 5 \\
207.5 \\
196 \cdot 0 \\
190.4 \\
207.0\end{array}$ & $\begin{array}{l}170 \cdot 8 \\
220 \cdot 2 \\
205 \cdot 2 \\
184.5 \\
203 \cdot 0\end{array}$ & $\begin{array}{l}182.4 \\
207.5 \\
200.5 \\
180.0 \\
200 \cdot 6\end{array}$ & $\begin{array}{l}190 \cdot 5 \\
210.4 \\
194 \cdot 4 \\
192.7 \\
208 \cdot 6\end{array}$ & $\begin{array}{r}18 \cdot 57 \pm 2 \cdot 4 \\
8 \cdot 25 \pm 1 \cdot 1 \\
3.00 \pm 0.9 \\
3 \cdot 20 \pm 1 \cdot 0 \\
2 \cdot 30 \pm 0.6\end{array}$ \\
\hline
\end{tabular}

Diabetes was induced in 30 rabbits by the method of Duffy. ${ }^{2}$ Alloxan monohydrate $150 \mathrm{mg} / \mathrm{kg}$ was infused as a $5 \%$ aqueous solution into the marginal vein of an ear. The rabbits developed diabetes in seven days. The 30 rabbits were then divided into five groups of six. After 18 hours' fasting each of four out of the five groups was given one of the test substances at a dose of $250 \mathrm{mg} / \mathrm{kg}$. Distilled water was given to the fifth group as a control. Blood glucose concentrations were then
measured at hourly intervals by the Folin-Wu measured at hourly intervals by the Folin-Wu
method as described by King and Wootton. The results (see table) showed that all the onion
extracts had antidiabetic-like activity. Their potency was expressed as maximum fall percentage potency was expressed as
on the blood glucose level.

It seems that the mode of action of onion extracts differs from that of tolbutamide. The principal action of tolbutamide is to stimulate release of insulin by the beta cells of the islets of Langerhans. Thus it is ineffective in alloxan-induced diabetes in rabbits. Onion extracts, however, have hypoglycaemic activity when insulin secretion by the pancreas is almost stopped. The hypoglycaemic action of onion may be to enable cells better to utilize glucose. The findings so far are encouraging and further work on the isolation and purification of the hypoglycaemic principles is warranted. We are grateful to B.D.H. Chemicals, London, for the supply of alloxan.-We are, etc.,

R. C. JAIN

C. R. VYAS

Department of Pathology and Biochemistry,

R.N.T. Medical College,

India

1 Jain, R. C., and Vyas, C. R., Lancet, 1973, 2, 2 Duffy, E., fournal of Pathology and Bacteriology, King, 57, 199. and Wootton, I. D. P., Microanalysis in Medical Biochemistry, p. 85. London, Churchill, 1957.

\section{Encroachments on the Patient's} Responsibility

SIR.-Writing about doctor/patient responsibilities, Mr. R. F. N. Duke (8 June, p. 557) paints his moral blacks too black and his whites too white. He ignores several lines of relevant argument.

Firstly, the legal position is not clear. If, after careful exposition of the risks by the doctor, the patient chooses to ignore the proferred advice, the surgeon agrees to carry out non-essential surgery nevertheless, and a greater or lesser tragedy results the surgeon's legal position may be in doubt and much more so in some other countries than in Britain. This is especially so in the case of the 10-day rule, where it might well be argued that the woman cannot waive her child's rights.

Secondly, the patient bears responsibility to the surgeon as well as the other way round. If a grossly obese patient fails even to attempt weight loss before undergoing planned major surgery it is at least arguable that the surgeon is within his rights and acting in everybody's best interests (including his own) in insisting on further delay method as described by King and Wootton. ${ }^{3}$
The results (see table) showed that all the onion 
until the patient shows better evidence of intention to co-operate in his treatment. When one operates on this sort of patient, especially through the abdomen, the main morbidity is to the surgeon's coronary arteries, both inter- and postoparatively.

Finally, many surgeons already do refuse to operate on non-co-operative patients. In Mr. Duke's own specialty numbers of orthopaedic surgeons will not do major hip replacements on grossly fat patients. Some vascular surgeons refuse major reconstructive surgery to patients who will not stop smoking. They argue that the effort and expense to the nation involved will, to an extent, be wasted in those patients who continue to indulge in the habit which was the main cause of their disease and will contribute to any failure of their surgery.

In each case, the taking of the medical advice may make the surgery unnecessary. -I am, etc.,

AlaN RHODES

Coventry

\section{Red Skin and Dorbanex}

SIR,-Over the past two years we have had four ward patients who developed bright red, sharply demarcated patches of skin either on the inner aspects of the thighs, along the line of the drainage tube of an indwelling catheter, or on the buttocks $\infty$ inciding with the area of contact with the bedpan rim. In spite of the apparent acute erythema the patients had no symptoms. The patches were characterized by the irregularity of the edges. The redness gradually faded without trace after the application of a diluted topical steroid. The common factors in all the patients were that they were elderly women, relatively or completely immobile, had had recent urinary tract infections, and had all been taking Dorbanex. There was no other drug common to all.

It is well known that danthron, the synthetic anthroquinone contained in Dorbanex, is excreted in the urine and can cause it to be coloured pink or red. Red staining of the perianal skin and of the buttocks in patients incontinent of faeces has been reported. The red colouration is an "indicator reaction" associated with an alkaline $\mathrm{pH}$ and is reversible. If red alkalinized Dorbanex is applied to normal skin under occlusion the acid pH of the skin is sufficient to reverse the colour change and no staining occurs. Though the appearance of the lesion was not that of a contact eczema we carried out conventional patch testing with red Dorbanex on the forearm skin of one of the patients with a negative result.

We postulate that for the red staining to occur both an alkaline urine, such as can occur with a urinary infection, and a skin devitalized by friction and some degree of maceration are required. We report these cases as they remained a puzzle to us for a considerable time and might provide a clue to the cause of similar skin lesions in other patients.-We are, etc.

MARY H. BUNNEY Bruntsfield Hospital,

ISABEL $M$. NOBLE Edinburgh
While we would all like the family planning issue resolved for many excellent reasons, it would be foolish in the extreme to concede this key, underpriced issue and enter the next round emptyhanded with so much at stake.-I am, etc.,

J. G. BALL

Bewdley, Worcs.

SrR,--The Review Body has reviewed. As an unmarried research registrar with inexpensive hospital accommodation and no dependants other than a thirsty motorcar, I have no personal complaint about my own financial status. I am sunprised, however, at the paltory increase offered to consuliants, and I think many are surprised that their slice was not greater. A government devoted to reducing private practice-a move with which I feel some sympathy-is very successfully increasing the incentive to find supplementary income.

What surprises me most of all is that many general practitioners seem to be under the impression that consultant pay is still the highest in the profession. Presumably this fallacy occurs because many G.P.s see more of those consultants to whom they refer private work. But I believe that a young consultant physician in a teaching hospital has some right to feel faintly jaundiced, if not frankly green, when his senior house officer leaves for general practice to earn considerably more there than the former chief will continue to earn.-I am, etc.

RichaRd CAMPBELI

\section{Review Body Report}

SIR,-Apart from the comment that the Review Body Report for 1974 might well have been written by the Health Departments themselves and just as well published on 1 April, I will only draw attention to the abysmal fact of the continuing lack of proper recognition of the senior status of senior hospital medical officers.

It is not merely a matter of experience but of continuing responsibility, as with consultants. Yet they are offered not one penny more than medical assistants, who are of intermediate status and who, like junior medical staff, are eligible for extra duty allowances. A hollow concession is the proposed addition to the S.H.M.O scale of the two top points of the medical assistant scale, surely a pathetic and meaningless gesture!

Every year that passes sees the perpetuation of this unfortunate anomaly and adds to one's doubits about the $\mathrm{Re}$ view Body's proper comprehension of the profession's problems.-I am, etc.,

\section{N. V. WILLIAMS}

Cefn Mably Hospital, St. Mellons,

SIR,-While the fourth Halsbury Report is more encouraging than its predecessors in attitude and understanding, there are still aspects giving rise to great concern. The recommendations show inadequate appre- ciation of such services as the manpower plight of general practice, the significance here of medical earnings abroad, and the economic value of out-of-hours service. What does shine through successfully above all else is the shortfall in medical earnings of at least 7\% since April 1972. This deficiency is greater in general practice and will exceed $£ 1,000$ per practitioner. Its effect is that every tenth hour on duty, item of service, house call, etc., remains unpaid for-and earnings-related pensions are reduced in consequence.

While this is no moment to man the barricades amidst the economic blizzard, it is certainly no time for complacency or concessions. We need now to make a firm signal of intent marked in a practical manner. We must withhold agreement on contraceptive services. These are significantly underpriced and it would be foolish in the extreme to extend our services and our contractual obligations when we are both hard-pressed and under-rewarded on our main contract.

Let our aspiring masters put aside procrastination, leam the obligations of "good employers," and settle our multitude of outstanding grievances (they know the list full well). This can usefully occupy the time until phase three restrictions are lifted and pay shortfall corrected; meanwhile the contraceptive services can be repriced by the Review Body given proper support from the Department of Health and Social Security.
SIR,-So we are to receive a derisory $7 \frac{1}{2} \%$ pay rise! At least I can now afford to go to
University of Sheffield, Royal Hospield
Sheffich

SIR,-I have just read that the annual capitation fee for family planning services has been fixed at $£ 1.72$. No wonder that the Government has accepted it at once! Having been paid a fee of $£ 5$ per annum by the county health committee for those social cases who could not afford family planning services, are we to expect now to be offered only a pittance for these extra services? I for one would not continue to accept a fee which I regand as ludiorous and I trust that it will be rejected by our professional body.

It is time we started to prepare plans for our withdrawal from the N.H.S. It is obvious that the present set-up is not properly financed and that an alternative method will have to be sought. To expect G.P.s to accept $6.5 \%$ increase in remuneration and at the same time compete with a 15$18 \%$ rate of inflation is a policy of disaster which no self-respecting doctor should be forced to accept.-I am, etc.,

T. D. RICHARDS Pucklechurch, near Bristol Academic Divis 